\title{
Synthesis and Conformations of A-B-A Tri-Block Copolymers with Hydrophobic Poly $(\gamma$-benzyl L-glutamate) and Hydrophilic Poly(ethylene oxide)
}

\author{
Kohei Kugo, Atsushi OHJI, Takeshi UnO, \\ and Jun NISHINO \\ Department of Applied Chemistry, Faculty of Science, Konan University, \\ Okamoto 8-9-1, Higashinada-ku, Kobe 658, Japan
}

(Received October 3, 1986)

\begin{abstract}
Polymerization of $\gamma$-benzyl $N$-carboxy-L-glutamate anhydride was initiated by the primary amino groups capped at both ends of poly(ethylene oxide) as the middle block component. Before the preparation, the terminal hydroxyl groups of the middle block were reacted with excess tosylchloride. Subsequent treatment of tosylated poly(ethylene oxide) with potassium phthalimide and refluxing of the resulting product with hydrazine hydrate afforded the primary amine-terminated poly(ethylene oxide). From the data of infrared spectroscopy, it was found that the polypeptide chain block in A-B-A type block copolymers obtained exists in the $\alpha$-helical conformation in the same manner as poly ( $\gamma$-benzyl L-glutamate). Furthermore, it has been suggested by the circular dichroism measurements in the solid state that the helical content of the polypeptide block chain decreases gradually by swelling in water depending on the treatment time and the molar amount of poly(ethylene oxide).

KEY WORDS Tri-Block Copolymer / Poly( $\gamma$-benzyl L-glutamate) / Poly(ethylene oxide) / Conformation / Circular Dichroism /
\end{abstract}

Studies on block copolymers containing poly $(\alpha$-amino acid) as one component were first reported by Yamashita et al. ${ }^{1}$ They synthesized A-B-A type tri-block copolymers with the method of the polymerization of $\gamma$-methyl $N$-carboxy-D-glutamate anhydride initiated by the primary amino groups capped at both ends of the polystyrene.

Gallot et al. subsequently prepared A-B diblock copolymers composed of polyvinyl block (polystyrene or polybutadiene) and a polypeptide block [poly ( $\gamma$-benzyl L-glutamate), poly( $\varepsilon$-carbobenzoxy L-lysine), or $\operatorname{poly}\left(N^{5}\right.$ hydroxypropylglutamine)], and evaluated the structural parameters of the lamellar structures of these block copolymers. ${ }^{2-5}$

The thrombogenic properties of A-B-A triblock copolymers composed of poly $(\gamma$-benzyl L-glutamate) and random copolymer of buta- diene/acrylonitrile were investigated taking notice of morphological order and macromolecular motions of polymer surfaces by Anderson et al. ${ }^{6,7}$

In previous studies, ${ }^{8-13}$ one of the authors (K.K.) synthesized A-B-A type tri-block copolymers composed of polybutadiene and a polypeptide block [poly $(\gamma$-benzyl L-glutamate), poly( $\varepsilon$-carbobenzoxy L-lysine), or $\operatorname{poly}(\gamma$ methyl D,L-glutamate)] and investigated not only structure but also other physicochemical properties such as permeability, surface morphology, surface chemical composition, and mechanical properties.

As described above, a hydrophobic polyvinyl block like polystyrene or polybutadiene has been used as another component of polypeptide block component.

In this study, our interest is in A-B-A type 
tri-block copolymers composed of hydrophilic poly(ethylene oxide) as a middle block component and hydrophobic poly $(\gamma$-benzyl Lglutamate) as outer polypeptide block components. Recently, it has been also elucidated that the modified bovine serum albumin by covalent attachment of poly(ethylene oxide) appears to lose its immunogenicity. ${ }^{14}$ Therefore, studies on block copolymers consisting of poly(ethylene oxide) and polypeptide are interesting from both synthetic and biomedical points of view. ${ }^{15}$

\section{EXPERIMENTAL}

\section{Synthesis and Purification of Materials}

Poly(ethylene oxide) (PEO). For the preparation of block copolymers, we first converted the terminal hydroxyl groups of the middle block component into more reactive primary amino groups, whose synthetic pathway has been reported by Mutter ${ }^{16}$ and others. ${ }^{17,18}$

Commercially available PEO, of which weight average molecular weight $\bar{M}_{w}=4000$ and molecular distribution $\bar{M}_{w} / \bar{M}_{n}=1.33$, was used to prepare di-aminated PEO by modified Mutter's method. ${ }^{16}$ All procedures are shown in Scheme 1.

Tosylated PEO (TsO-PEO). First of all, dry PEO was reacted with excess tosylchloride in $10 \mathrm{ml}$ methylene dichloride (13 equivalent) in pyridine $(6 \% \mathrm{w} / \mathrm{v})$ at $0^{\circ} \mathrm{C}$ for 4 days to produce TsO-PEO, which was purified by precipitation with excess diethyl ether.

Di-phthalimido PEO (PI-PEO). To a solution of TsO-PEO in dimethylformamide $(9 \% \mathrm{w} / \mathrm{v}) 3 \mathrm{eq}$. potassium phthalimide were added. The solution was stirred under nitrogen at $118-120^{\circ} \mathrm{C}$ for $3 \mathrm{~h}$, and precipitated in excess diethyl ether.

Amine-Terminated PEO (ATPEO). PI-PEO in ethanol $(5 \% \mathrm{w} / \mathrm{v})$ was subsequently refluxed for $3 \mathrm{~h}$ with excess hydrazine hydrate $(20$ equivalent) and filtered off prior to precipitation of primary amine-terminated PEO
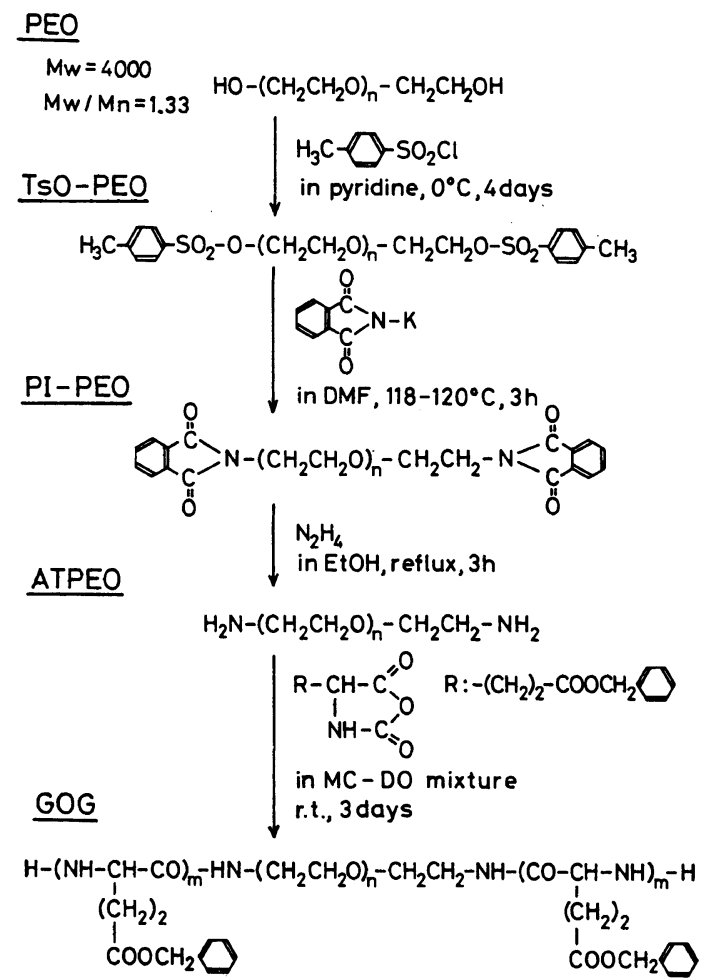

Scheme 1. Synthesis of A-B-A tri-block copolymers consisting of poly( $\gamma$-benzyl L-glutamate) (A) and poly(ethylene oxide) (B).

(ATPEO). The final product ATPEO in warm ethanol was purified by precipitation with diethyl ether and then dried in vacuo.

Degree of Amination. For the determination of the terminal amino groups, a small amount of ATPEO solution in $3 \mathrm{ml}$ glacial acetic acid was titrated to a blue end-point with $0.01 \mathrm{~N}$ perchloric acid in glacial acetic acid by using crystal violet as the indicator. ${ }^{19,20}$ Thymol blue was not used as the indicator because its endpoint was somewhat opaque.

$\gamma$-Benzyl-L-glutamate $\quad N$-Carboxyanhydride $(\gamma-B L G-N C A)$. The monomer, $\gamma$-BLG-NCA, was prepared according to the method proposed by Blout and Karlson ${ }^{21}$ and purified by repeated recrystallization from an ethyl acetate solution with the addition of petroleum ether.

Synthesis of Block Copolymers. The respective amounts of $\gamma$-BLG-NCA and ATPEO 
were calculated to obtain the desired degree of the polypeptide block. The polymerization was carried out in the absence of moisture at room temperature in a methylene dichloridedioxane $(2: 1, \mathrm{v} / \mathrm{v} \%)$ mixture at a total concentration of $5 \% \gamma$-BLG-NCA and ATPEO, as shown in Scheme 1. All solvents used for synthesis were purified more than two times by the usual methods. After 3 days, the polymerization was terminated, and the copolymer was precipitated by 5 volumes of pure cold methanol. This method of precipitation allowed the elimination of traces of ATPEO and amino acid-NCA still present, and the oligopeptide formed by autopolymerization. ${ }^{22}$ Then A-B-A type tri-block copolymer (GOG) was dried in vacuo for physical measurements.

\section{Molecular Weights and Molecular Weight Distribution}

The molecular weights and molecular weight distributions of PEO, ATPEO, and the tri-block copolymers were estimated from gel permeation chromatography (GPC) measurements using Shimadzu GPC Model LC-5A and RID-2A detector. Two HSG columns (each $7.9 \mathrm{~mm}$ inner diameter and $30 \mathrm{~cm}$ length), HSG-20S and HSG-50S, were used. The carrier solvent was tetrahydrofuran (THF) and its flow rate was $1 \mathrm{ml} \mathrm{min}^{-1}$. The injections were usually $0.4 \mathrm{ml}$ of $0.1 \mathrm{w} / \mathrm{v} \%$ stock solutions. The calibration curve by using standard polystyrene was prepared before the measurements.

\section{Composition of Block Copolymers}

The molar composition of GOG block copolymers was determined by elemental analysis and GPC measurements.

\section{Conformation of the Polypeptide Blocks}

Infrared spectra (IR) of solid films of the samples cast from chloroform (CF) solution were measured with Hitachi Model EPI-G3 IR spectrophotometer in the region of 4000 to $400 \mathrm{~cm}^{-1}$. Circular dichroism (CD) spectra were measured at room temperature by a JASCO MODEL ORD/UV-5 equipped with CD measurements apparatus. The samples were cast from $\mathrm{CF}$ solution on the quartz cell, and dried at $25^{\circ} \mathrm{C}$ and at a relative humidity less than $60 \%$. Their rinse treatment was carried out by holding them in running distilled water for $1 \mathrm{~min}$.

\section{RESULTS AND DISCUSSION}

\section{Materials}

$A T P E O$. As described previously, commercially available $\mathrm{PEO}$ was used for a middle block component, of which weight-average molecular weight $\bar{M}_{w}=4000$ and molecular weight heterogeneity $\bar{M}_{w} / \bar{M}_{n}=1.33$ from GPC measurements.

Starting from PEO, all intermediate products were confirmed by IR spectra as follows. ${ }^{23,24}$ For TsO-PEO, at first, four characteristic bands were observed at $1170 \mathrm{~cm}^{-1}$ (symmetric $\mathrm{SO}_{2}$ stretching, $v_{\mathrm{s}} \mathrm{SO}_{2}$, of sulfonate ester), 1005 and $1030 \mathrm{~cm}^{-1}\left(\mathrm{C}_{6} \mathrm{H}_{4}\right.$ in-plane bending, para-disubstituted aromatic), and $815 \mathrm{~cm}^{-1}\left(\mathrm{C}_{6} \mathrm{H}_{4}\right.$ out-of-plane bending, paradisubstituted aromatic). Then for PI-PEO next to TsO-PEO, one characteristic band was observed at $1720 \mathrm{~cm}^{-1}$ (phthalimide) while the band at $1170 \mathrm{~cm}^{-1}$ due to $v_{\mathrm{s}} \mathrm{SO}_{2}$ disappeared. Subsequently for ATPEO, characteristic peaks were observed at $1465 \mathrm{~cm}^{-1}\left(\mathrm{CH}_{2}\right.$ symmetric bending, $\left.\delta_{\mathrm{s}} \mathrm{CH}_{2}\right), 1120$ and $1060 \mathrm{~cm}^{-1}(\mathrm{C}-\mathrm{O}-\mathrm{C}$ asymmetric stretching, $\left.\quad v_{\text {as }} \mathrm{C}-\mathrm{O}-\mathrm{C}\right), \quad$ and $1600 \mathrm{~cm}^{-1}\left(\mathrm{NH}_{2}\right.$ in-plane bending, $\left.\delta \mathrm{NH}_{2}\right)$, while the band at $1720 \mathrm{~cm}^{-1}$ disappeared.

The solubility of ATPEO was similar to that of PEO and as a result of titration in glacial acetic acid with perchloric acid, we obtained the degree of amination $f\left(\mathrm{NH}_{2}\right)=1.98$, which means that both ends of ATPEO are almost perfectly capped by primary amino groups.

From experimental results on GPC measurements, furthermore, both the weight-average molecular weight and molecular weight heterogeneity of ATPEO were the same as 
those of PEO, respectively. TsO-PEO was produced at $0^{\circ} \mathrm{C}$ to prepare ATPEO from PEO as mentioned above, because the molecular weights of ATPEO induced from TsO-PEO at $25^{\circ} \mathrm{C}$ were rather lower than $\bar{M}_{w} 4000-20000$ of the first PEO. Thus we obtained primary amine-terminated ATPEO which was subsequently used for the middle block component. In the case of the primary amineinitiated polymerization of the $\alpha$-amino acid NCA, it is well known that the initiator amine

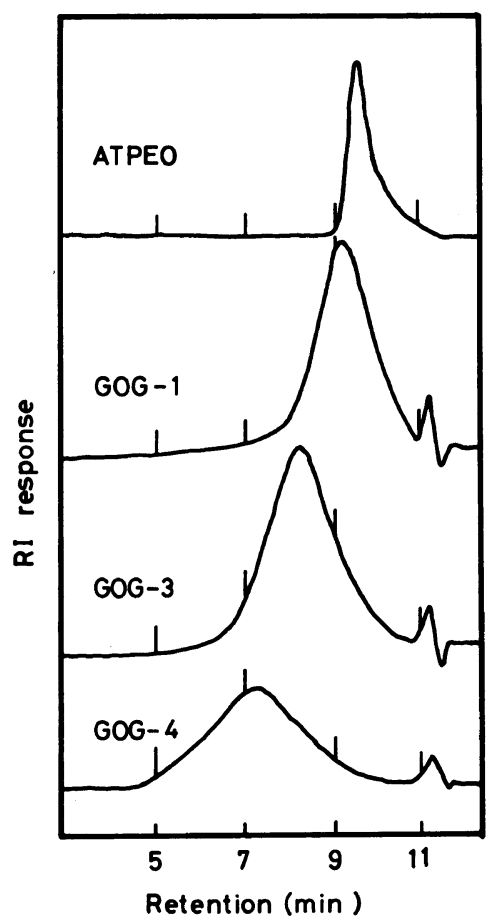

Figure 1. Molecular weight heterogeneity of ATPEO and GOG, as estimated by GPC in THF solution. undergoes a nucleophilic addition to the C-5 carbonyl group of the NCA. This mechanism thus affords the block copolymers.

Block Copolymers. Figure 1 shows the GPC diagram plotted against retention time for ATPEO and GOG block copolymers, in THF solution. The experimental chromatograms for GOG samples show a very small tailing of the main component towards the larger retention time side and a single rather sharp peak similar to that of ATPEO. This may mean that the copolymers are sufficiently homologous with respect to both molecular weight and composition. The small peak existing at the larger retention time side of each main peak is due to the injection solvent.

Table I summarizes the molecular characterization of GOG block copolymers by GPC measurements. The copolymer composition is denoted by molar percent of the A component and $P_{\mathrm{A}}$ means the degree of polymerization of the A block chain. As is shown in Table I, molar compositions of the A component are in the range of about 36 to $86 \%$. The $\bar{M}_{w}$ values of them were in the range of 15000 to 125000 . The molecular weight distributions were relatively sharp and toward 1.8 .

\section{Conformation of the Polypeptide Blocks}

The IR spectra of typical representative GOG-5 block copolymer and PBLG in the region of $4000-400 \mathrm{~cm}^{-1}$ are shown in Figure 2. Amide A, amide I, II, and $\mathrm{V}^{25,26}$ bands of GOG-5 appear at ca. 3290, 1650, 1545, and $610 \mathrm{~cm}^{-1}$, respectively, as is the case for PBLG homopolymer. This suggests that the G-block

Table I. Molecular characterization of A-B-A tri-block copolymers composed of poly( $\gamma$-benzyl L-glutamate) (A) and poly(ethylene oxide) (B)

\begin{tabular}{cccccc}
\hline Designation & $\mathrm{A} / \mathrm{mol} \%$ & $P_{\mathrm{A}}$ & $\bar{M}_{w} \times 10^{-4}$ & $\bar{M}_{n} \times 10^{-4}$ & $\bar{M}_{w} / \bar{M}_{n}$ \\
\hline GOG-1 & 35.6 & 25 & 1.5 & 0.8 & 1.88 \\
GOG-2 & 48.8 & 44 & 2.3 & 1.0 & 2.30 \\
GOG-3 & 68.4 & 98 & 4.7 & 2.6 & 1.81 \\
GOG-4 & 77.4 & 155 & 7.2 & 3.8 & 1.89 \\
GOG-5 & 85.9 & 276 & 12.5 & 7.2 & 1.74 \\
\hline
\end{tabular}




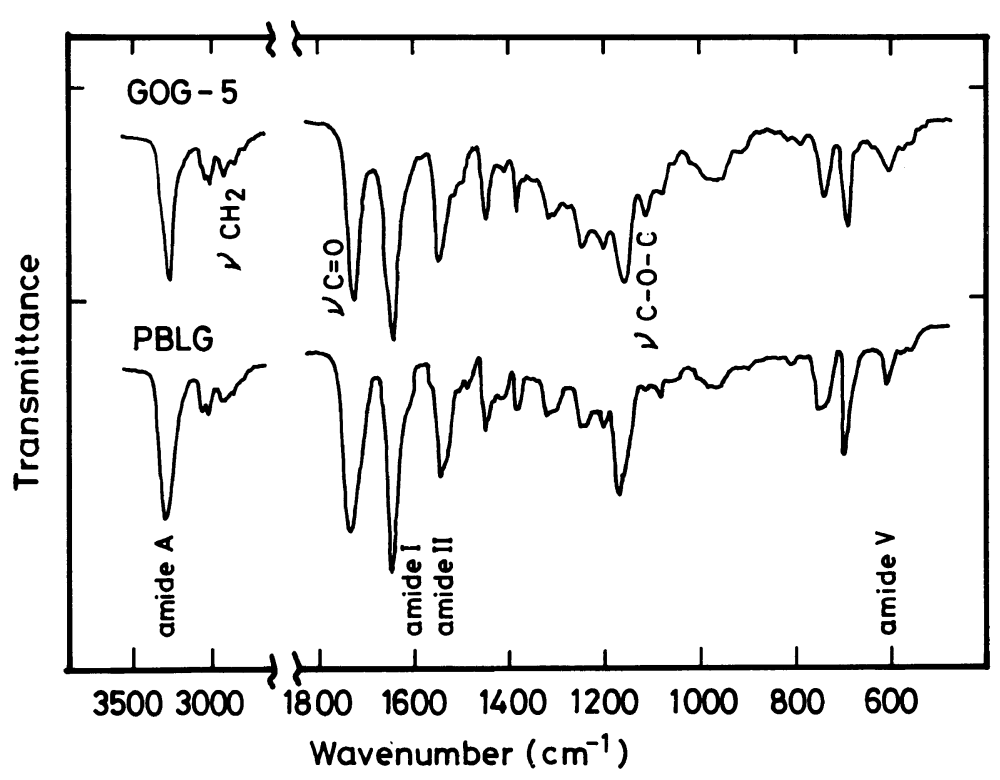

Figure 2. Infrared spectra of films of GOG-5 and PBLG cast from chloroform.
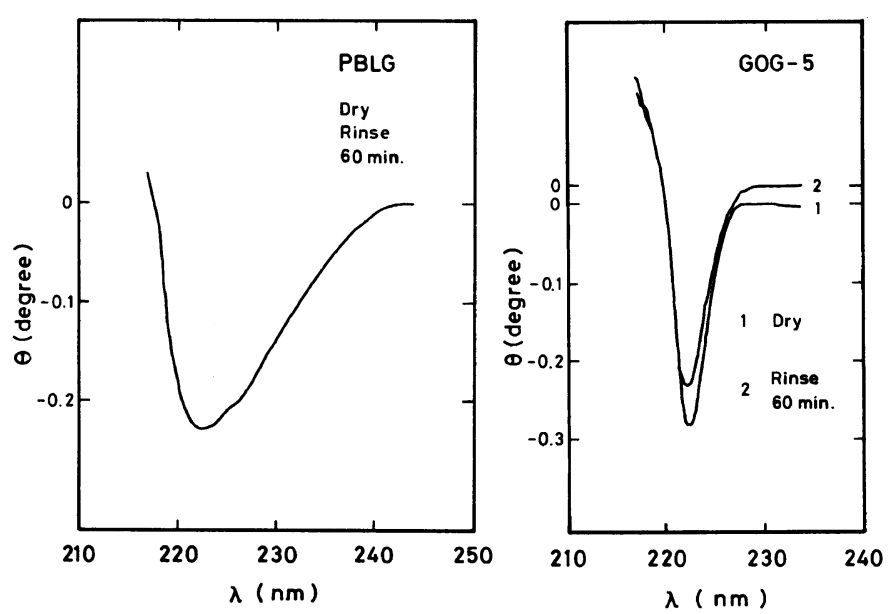

Figure 3. Circular dichroism spectra of PBLG and GOG-5 block copolymer in the solid state.

component in GOG-5 block copolymer assumes an $\alpha$-helical conformation and that the helical content of GOG-5 block copolymer is nearly the same as that of PBLG homopolymer. Specific bands of GOG-5 were furthermore observed at 2925 and $2850 \mathrm{~cm}^{-1}\left(\mathrm{CH}_{2}\right.$ stretching), $1730 \mathrm{~cm}^{-1} \quad(\mathrm{C}=\mathrm{O}$ stretching of ester), and $1115 \mathrm{~cm}^{-1}(\mathrm{C}-\mathrm{O}-\mathrm{C}$ asymmetric stretching). Characteristic bands of other block copolymers obtained were similar to those of GOG-5.

Figure 3 shows the CD spectra of PBLG and GOG-5 block copolymer in the solid state cast from CF solution on the quartz cell. For PBLG, rinsing by water and swelling in water at room temperature for $60 \mathrm{~min}$ gave almost the same negative peaks (i.e., the same intensity) as untreated dry PBLG film at $222 \mathrm{~nm}$. 

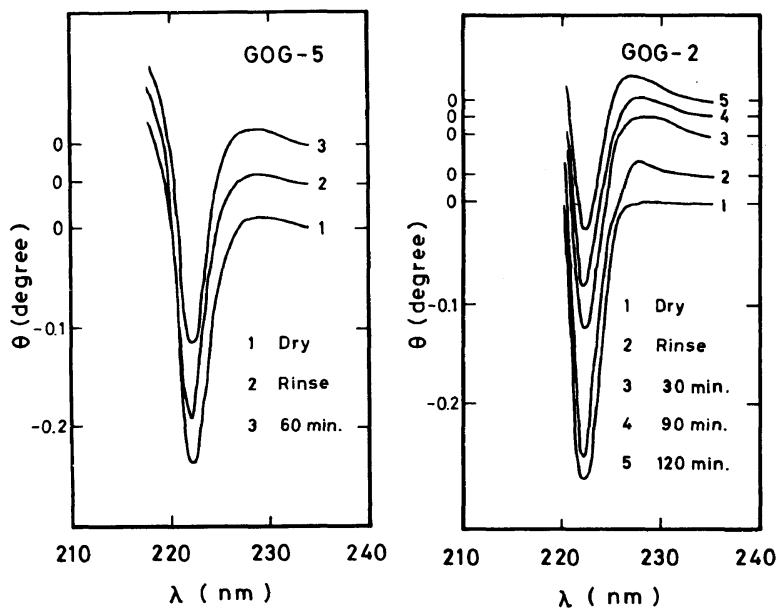

Figure 4. Circular dichroism spectra of GOG-5 and GOG-2 in the swollen state.

It is well known that this negative $222 \mathrm{~nm}$ band assigned to the $n-\pi^{*}$ transition is characteristic of an $\alpha$-helical conformation. ${ }^{27}$ This means that PBLG exists in the $\alpha$-helical conformation in both states of dryness and wetness by water because of the hydrophobicity. In the case of GOG-5, the CD spectra in the dry solid state also gave a similar negative but somewhat narrower peak than that of PBLG at the same position $(222 \mathrm{~nm})$. The peak intensity of rinsetreated GOG-5, however, decreased compared with that of dry GOG-5. This means the helical content of the G-component decreased by rinse treatment.

Subsequently the CD spectra of GOG-5 and GOG-2 treated with pseudo-extracellular fluid $(\mathrm{PECF})^{28}$ instead of water measured to check the conformation changes under physiological condition. As in Figure 4, the peak intensity of both GOG-5 and GOG-2 decreased with an increase in the swelling time. It is then considered that water clusters in hydrophilic PEO domains sterically hinder the $\alpha$-helical conformation and form the hydrogen bondings with polypeptide backbone, and then destroy some positions of the $\alpha$-helical conformation.

In summary, we at first converted the hydroxyl groups at both ends of PEO into pri- mary amino groups, and prepared A-B-A type tri-block copolymers composed of PBLG and PEO. Structural studies furthermore elucidated that G-block component of GOG block copolymers obtained assume the same $\alpha$-helical conformation as the corresponding PBLG homopolymer. However, the helical content of G-block component decreases gradually by swelling in water depending on the swelling time and molar amount of PEO component.

Acknowledgments. This research was supported by the Grant-in-Aid from Hyogoken Kagaku-gijutsu Shinko Zaidan. The authors wish to express their sincere gratitude for the financial assistance.

\section{REFERENCES}

1. Y. Yamashita, Y. Iwaya, and K. Ito, Makromol. Chem., 176, 1207 (1975).

2. J. P. Billot, A. Douy, and B. Gallot, Makromol. Chem., 177, 1889 (1976).

3. B. Perly, A. Douy, and B. Gallot, Makromol. Chem., 177, 2569 (1976).

4. A. Douy and B. Gallot, Polym. Eng. Sci., 17, 523 (1977).

5. J. P. Billot, A. Douy, and B. Gallot, Makromol. Chem., 178, 1641 (1977).

6. S. A. Barenberg, J. S. Schultz, J. M. Anderson, and P. H. Geil, Trans. Am. Soc. Artif. Intern. Organs, 25, 159 (1979). 
7. S. A. Berenberg, J. M. Anderson, and K. A. Mauritz, J. Biomed. Mater. Res., 15, 231 (1981).

8. A. Nakajima, T. Hayashi, K. Kugo, and K. Shinoda, Macromolecules, 12, 840 (1979).

9. A. Nakajima, K. Kugo, and T. Hayashi, Macromolecules, 12, 844 (1979).

10. A. Nakajima, K. Kugo, and T. Hayashi, Polym. J., 11, 995 (1979).

11. A. Nakajima, K. Kugo, T. Hayashi, and H. Sato, "Biomedical Polymers," E. P. Goldberg and A. Nakajima, Ed., Academic Press Inc., New York, 1980, p 243.

12. K. Kugo, T. Hayashi, and A. Nakajima, Polym. J., 14, 391 (1982).

13. K. Kugo, M. Murashima, T. Hayashi, and A. Nakajima, Polym. J., 15, 267 (1983).

14. A. Abuchowski, Theo van Es, N. C. Palczuk, and F. Davis, J. Biol. Chem., 252, 3578 (1977).

15. K. Kugo, T. Uno, H. Yamano, J. Nishino, and H. Masuda, Kobunshi Ronbunshu, 42, 731 (1985).

16. M. Mutter, Tetrahedron Lett., 31, 2839 (1978).

17. K. Geckeler, Polym. Bull., 1, 427 (1979).
18. W. Kern, S. Iwabuchi, H. Sato, and V. Bohmer, Makromol. Chem., 180, 2539 (1979).

19. M. Sela and A. Berger, J. Am. Chem. Soc., 77, 1893 (1955).

20. M. Sela and A. Berger, J. Am. Chem. Soc., 75, 6350 (1953).

21. E. R. Blout and R. H. Karlson, J. Am. Chem. Soc., 78, 941 (1956).

22. A. Cosani, E. Peggion, E. Scoffone, and A. Portolan, Biopolymers, 4, 695 (1966).

23. K. Nakanishi, P. H. Solomon, and N. Furutachi, Ed., "Infrared Absorption Spectroscopy," Nankodo Co., Tokyo, 1978.

24. C. J. Pouchert, Ed., "The Aldrich Library of FT-IR Spectra," Aldrich Chemical Company, Inc., 1985.

25. T. Miyazawa and E. R. Blout, J. Am. Chem. Soc., 83, 712 (1961).

26. T. Miyazawa, Y. Masuda, and K. Fukushima, $J$. Polym. Sci., 62, S62 (1962).

27. G. Holtzwarth and P. Doty, J. Am. Chem. Soc., 87, 218 (1965).

28. C. A. Homsy, J. Biomed. Mater. Res., 4, 341 (1970). 